\title{
Acoustic emission techniques for the detection of simulated failures in historical vehicles engines
}

\author{
Laura Brambilla ${ }^{1, \mathrm{a}}{ }_{\mathbb{D}}$, Brice Chalançon ${ }^{2}$, Alejandro Roda Buch ${ }^{1,3}$, Emilie Cornet $^{1}$, \\ Guillaume Rapp ${ }^{1}$, Stefano Mischler ${ }^{3}$ \\ ${ }^{1}$ Haute Ecole Arc Conservation-Restauration, HES-SO University of Applied Sciences and Arts Western \\ Switzerland, Espace de l'Europe 11, 2000 Neuchâtel, Switzerland \\ 2 Association de Gestion du Musée National de L'Automobile, 188 Av. de Colmar, 68100 Mulhouse, France \\ ${ }^{3}$ Ecole Polytechnique Fédérale de Lausanne, EPFL, 1015 Lausanne, Switzerland
}

Received: 6 November 2020 / Accepted: 26 May 2021

(C) The Author(s) 2021

\begin{abstract}
Technical and industrial heritage artefacts are characterized by the presence of mechanisms. The possibility to activate, or reactivate, these mechanisms is an integral part of the cultural values of this kind of patrimony. The artefacts' functionality, however, requires an effective diagnostic in order to detect the onset of malfunctioning at a very early stage to avoid wear and breakdowns. The assessment of moving mechanisms of heritage objects may be performed using non-destructive methods, such as acoustic emission (AE). The ACUME_HV project aimed at developing diagnostic and monitoring protocols for historical vehicles' engines using AE techniques. The case studies were performed on 2-cylinders Renault AG1 vehicles (collection of the "Musée National de l'Automobile - Collection Schlumpf" of Mulhouse, France). These cars are maintained in working conditions, and their engines are started periodically. After a first phase consisting in recording the reference signals of the selected engines, the project focused on detecting faults simulated on purpose, the latter reproducing common failures occurring in historical vehicles' engines.
\end{abstract}

\section{Introduction}

In the field of cultural heritage, artefacts belonging to industrial, technical and scientific patrimony are part of a very specific category of objects, characterized by the presence of a mechanism. The mechanisms' functionality is considered as part of the cultural values of this heritage, and it should be maintained as long as the object's integrity is not at risk. Stopping indefinitely the movement of the mechanical parts makes the artefact lose part of its value.

As a consequence, maintaining the mechanisms in good functioning state should be a priority. Further, the material authenticity should also be preserved and, as a general rule, a complete replacement of the mechanisms' parts should be avoided.

However, the accurate and early diagnostic of the mechanisms' functioning state is particularly challenging for the conservators in the field. It requires specific expertise, and the standard procedure consisting of a complete disassembling of the mechanism implies usually great dedication from the personnel in charge.

\footnotetext{
a e-mail: laura.brambilla@he-arc.ch (corresponding author)
} 
To overcome these issues, the use of monitoring techniques belonging to the category of Non-Destructive Testing (NDT) may be considered. These techniques allow to perform a preliminary diagnostic without any need of dismantling completely the mechanical parts. This a priori assessment of the state of conservation of a mechanism provides the personnel with the necessary information to decide whether the movement can be started without causing damage to the artefact or if a complete or partial disassembling is necessary.

Amongst the NDT techniques, acoustic emission (AE) was considered as adapted to the case of historical vehicles as it relies on completely noninvasive methods [1].

AE is already known and used in the field of automotive industry in the context of faults' diagnostic of newly produced engines [2-10]. However, adapting similar AE methods to historical vehicles is more complex mostly due to the presence of oxidation products, residues, dust and scaling of lubricants. Despite the extended use of the AE technique in new engines assessment, the efficiency of this technique to provide reliable diagnostic results is still a challenge in the field of cultural heritage.

In the field of cultural heritage, AE has already been applied to topics such as monitoring of historical masonry and decorations [11-15] as well as music instruments [16] and other artefacts [17]. Nevertheless, to the extent of the knowledge of the authors, AE was considered for the first time for the monitoring of historical vehicles' engines in the framework of the ACUME_HV project [18-22]. In the first phase of the ACUME_HV project, the optimal locations of the sensors for the collection of the AE signals were identified, as the ones exhibiting the higher signal levels, combined with lower signal-to-noise ratio [18, 19]. Consequently, the AE measurements were performed on three distinct Renault engines type AG1 (Fig. 1), all belonging to the collection of the Musée National de l'Automobile de Mulhouse, France (MNAM) [21, 22]. This model of engine was chosen based on the following considerations:

- Mechanical simplicity of the engine. Having only two cylinders and basic auxiliary systems, the AG1 renders the assessment less complex.

- Easy accessibility. Most of the parts of the engine are accessible without undue burden, even when assembled in the vehicle.

- Availability. Three identical engines (AG1) are present in the collection of MNAN, two of them still in working conditions [23] and one, so-called bench engine [22] that was previously bought as spare part for possible reparations.

The AE measurement allowed to distinguish and identify the specific signals generated by friction and/or impacts for different contact pairs of the engine mechanisms, such as: crankshaft/connecting-rod, connecting-rod/piston, piston-rings/cylinder-liner, as well as those originating from inside the cam chain system. The airflow or air leakage at valve inlets/outlets and between piston-ring/cylinder-liner gaps could also be isolated. The following task of the project has been to obtain the acoustic signatures of the engine corresponding to the different reactivation conditions (such as with/without cylinder compression). Subsequently, statistical analysis techniques were used to extract specific features that could further be used to classify the operational state of the mechanical parts of the engine [18-22].

For the sake of assessing the reliability of the AE techniques to detect specific faults at their early stage in historical vehicles' engines, some, common, malfunctions have been artificially induced in the "bench engine" and their signals recorded. This paper specifically presents the results related to these faults' monitoring measurements. 


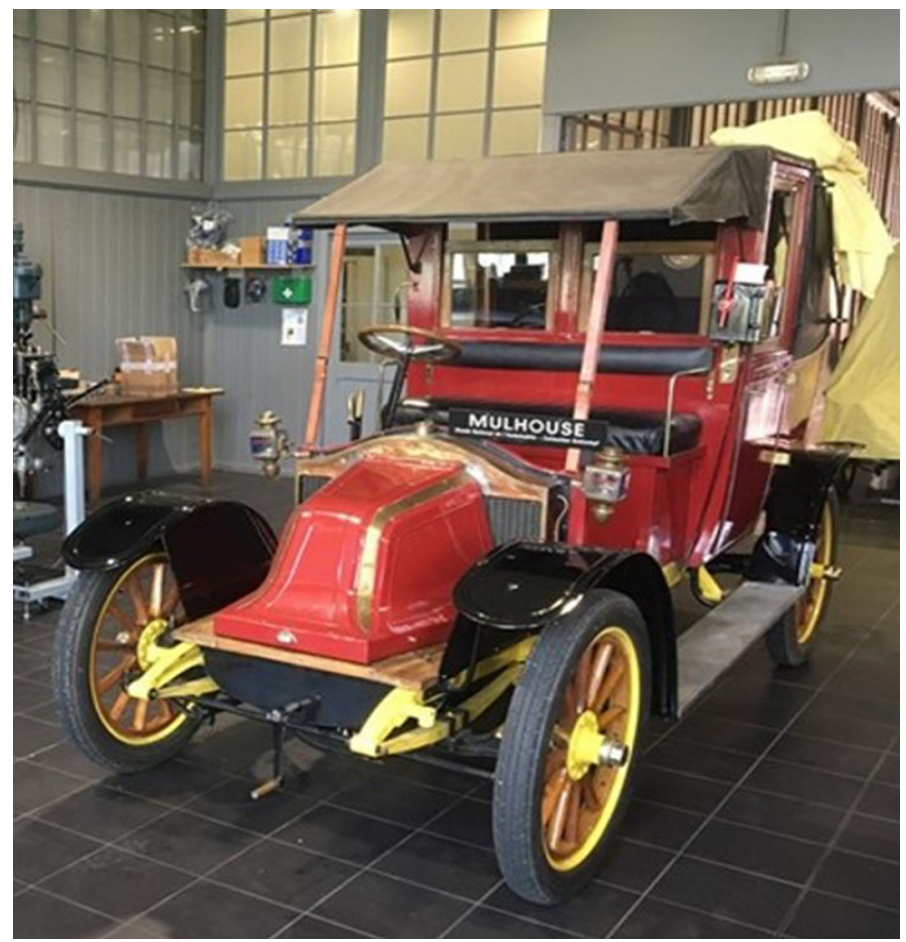

Fig. 1 Renault AG1 with a two cylinder engine @MNAM 2019

\section{Methodology}

An AE system from Vallen ${ }^{\circledR}$ was used to acquire the AE signals. The set-up includes a MB2-V1 chassis providing four AE and four parametric input channels. The system was equipped with four broadband AE sensors VS900-M (between 100 and $900 \mathrm{kHz}$ ) and their respective AEP5 preamplifiers (+34 dB). The sampling frequency of the AE signals was set to $2 \mathrm{MHz}$. A $1 \mathrm{MHz}$ low pass filter was applied to the input signals, in order to reduce the noise arriving from the high frequencies. The crankshaft angular position was additionally measured using a full continuous $360^{\circ}$ smart position sensor VISHAY Spectrol 601-1045 (output signal $0-5 \mathrm{~V}$ ) at a sampling rate of $1.25 \mathrm{kHz}$. A block diagram of the experimental set-up is sketched in Fig. 2a, and the corresponding acquisition system is shown in Fig. $2 \mathrm{~b}$.

The simulations of faults and the corresponding AE measurements were performed on one of the AG1 engines, previously removed from a vehicle and mounted on a test bench, in order to have complete access to all the parts of the engine itself. This engine will be called "bench engine", hereafter.

The location of the AE sensors around the engine was established in a previous phase of the ACUME_HV project [22], and the final determined locations of the four AE sensors are shown in Fig. 3. Two sensors were placed on the cylinder block: the first one (Sensor n.1) on the outer part of the first cylinder, the one closer to the car front when the engine is assembled in the car; the second one (Sensor n.2) on the opposite side, close to the first cylinder valves. The other two sensors were placed on the crankcase: one (Sensor n.3) on the cover of the gears of the cam system; the last one (Sensor n.4) on the crankcase leg. 
(a)
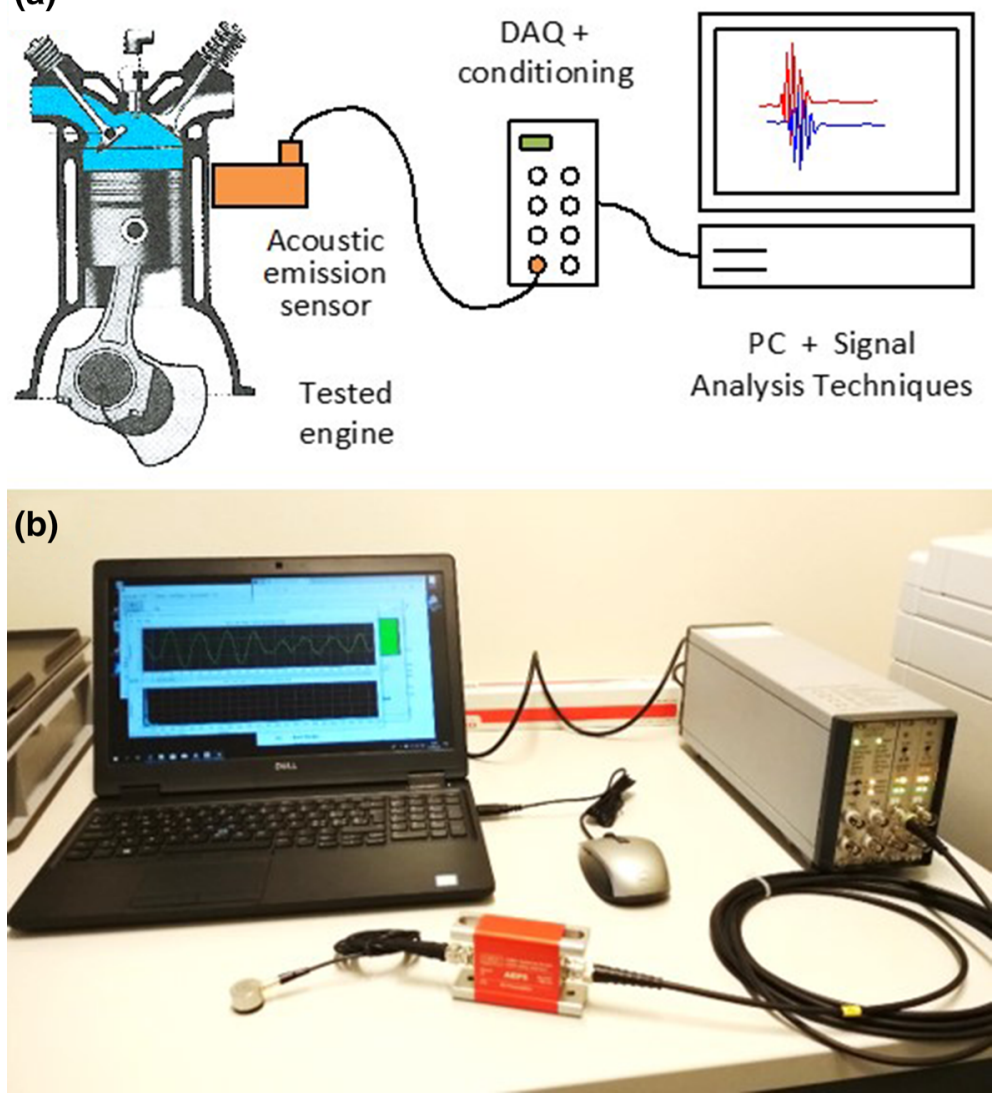

Fig. 2 a Block diagram of the experimental set-up; $\mathbf{b}$ Vallen ${ }^{\circledR}$ measurement system of AE signals

The mechanical parts of the engine were manually operated at a relatively low rotating speed using an external handle to move the crankshaft. This procedure allows one to keep good control of the different parts interaction during pistons slow motion, hence avoiding possible damage to the machine. This operation mode is in line with museum standards. In order to extract the mechanical and air compression signature of the engine in "cold test" conditions, the Root Means Square of the AE signals (AE rms) was used as a feature. The rms was calculated for blocks of signal with a period of $10 \mathrm{~ms}$. This feature is related with the AE signal energy generated, for example, by sliding friction processes in contact pairs [4]. The previous studies performed to determine the influence of the engine speed on the AE rms feature showed that there is a high correlation between the AE rms feature and the crankshaft angular position and, consequently, the relative motion of the piston to the cylinder [22]. Since the engine is moved by hand, the crankshaft rotational speed along the test is not constant, due to the variable resistance torque of the engine during its motion. Therefore, in order to compare the AE rms feature for different crankshaft positions obtained at different speeds along the same test as well as between different repeated tests, a normalization of the AE rms feature to a defined crankshaft rotational speed of $0.5 \mathrm{cps}$ (cycles per second) was performed. This speed was selected as it can be easily reached in "cold tests" with and 

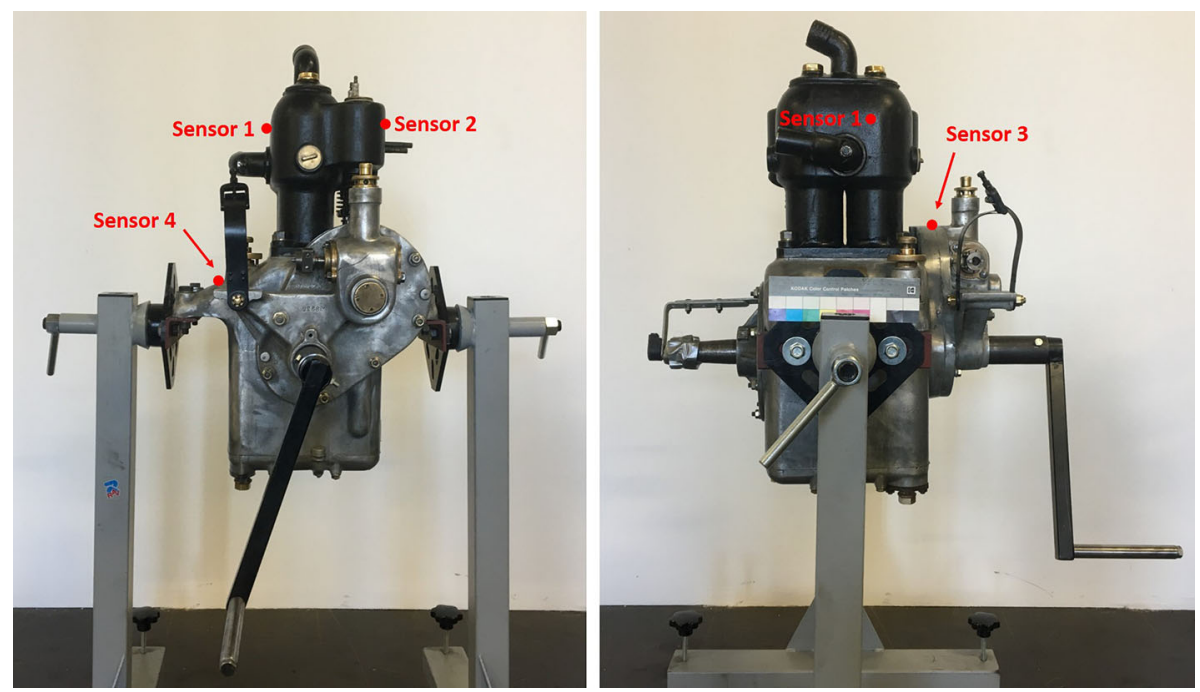

Fig. 3 AE sensors location on the Renault AG1 bench engine @MNAM 2019

without air compression inside the cylinders [22]. The whole procedure and bench set-up for AE measurements on historical vehicles' engines have already been described by the authors elsewhere [18-22].

Various failures simulations were generated, based on the possible detection of the failure as previously assessed taking into account the specific design of the engine. The failures that could be detected during cold tests, meaning without starting the engine, have been selected. Three types of faults were considered as follows:

1. The clearance between the connecting rod and the crankshaft (connecting rod failure) In order to simulate the clearance between the connecting rod and the crankshaft, the lower case of the engine was removed so that the connecting rod n. 1 could be reached (Fig. 4). One-millimeter-thick shims have been inserted between the connecting rod and the connecting rod cap, prior to reassembling the mechanical parts.

2. The clearance between the piston pin and the connecting rod

To simulate the clearance between the connecting rod and the piston pin, the engine block and piston $\mathrm{n} .1$ have been removed. A piston pin having a local reduction in diameter around its longitudinal center of $0.8 \mathrm{~mm}$ compared to the original pin was manufactured on purpose and reassembled with the connecting rod (Fig. 5). Therefore, the reduced diameter of the pin was placed in the location where the connecting rod is positioned thus creating a controlled clearance between these parts.

3. The wear of the piston rings

The test related to the simulation of faulty piston rings due to wear was performed by removing the rings of the piston n.1 (Fig. 6).

Subsequent to the three fault simulations, the circuits of the AG1 engine under investigation that had been emptied of cooling liquid and lubricant, prior to all the three tests have been refilled and the AE response of the engine during additional cold tests was recorded. 


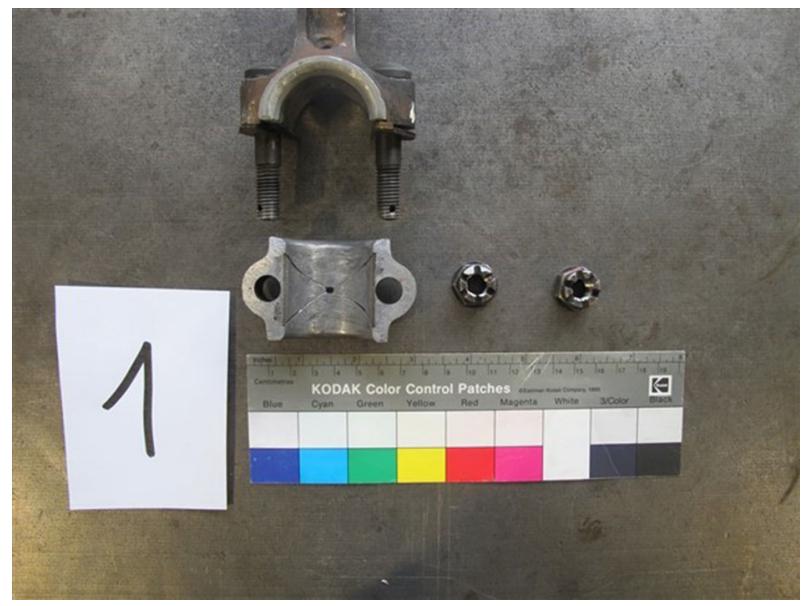

Fig. 4 Connecting rod cap n.1 removed for installing the shims @MNAM 2019

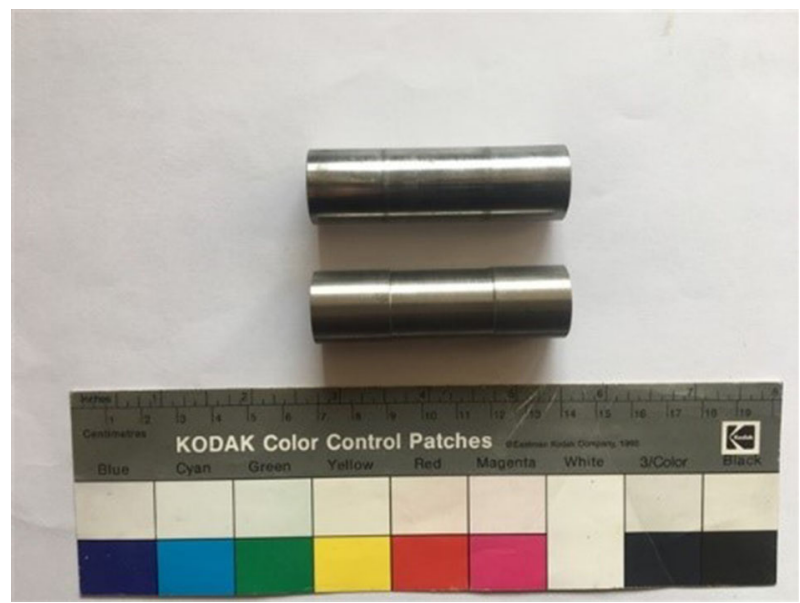

Fig. 5 On top: original engine's piston pin; at the bottom: new piston pin manufactured with a smaller diameter in the center, where the connecting rod is located @MNAM 2019

\section{Results}

For each simulated faults test mentioned in the methodology section, only the signals recorded with the sensors giving the most significant information are reported hereafter. The normalized AE rms signals against the crankshaft angular position are plotted in Figs. 7, 8, 9, 1011,12 and 13. The crankshaft rotation evolves for two complete thermodynamic cycles $\left(0-720^{\circ}\right)$, as reported in Table 1 . The first cycle is indicated in blue and second cycle in red, in the figures, corresponding to four full revolutions of the crankshaft (see details in Table $1)$.

To allow a comparison between the reference signals initially recorded for this engine and the signals recorded under the simulated faults conditions, the reference curves, with and without spark plugs assembled, are reported in Figs. 7 and 8 [19], for the four channels. For 


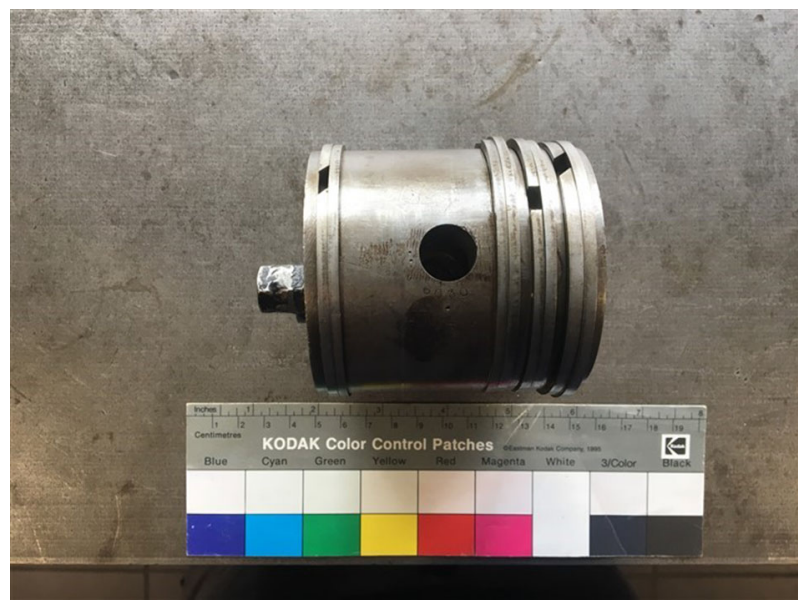

Fig. 6 Piston n.1 that has then been modified to simulate the wear of the rings CMNAM 2019
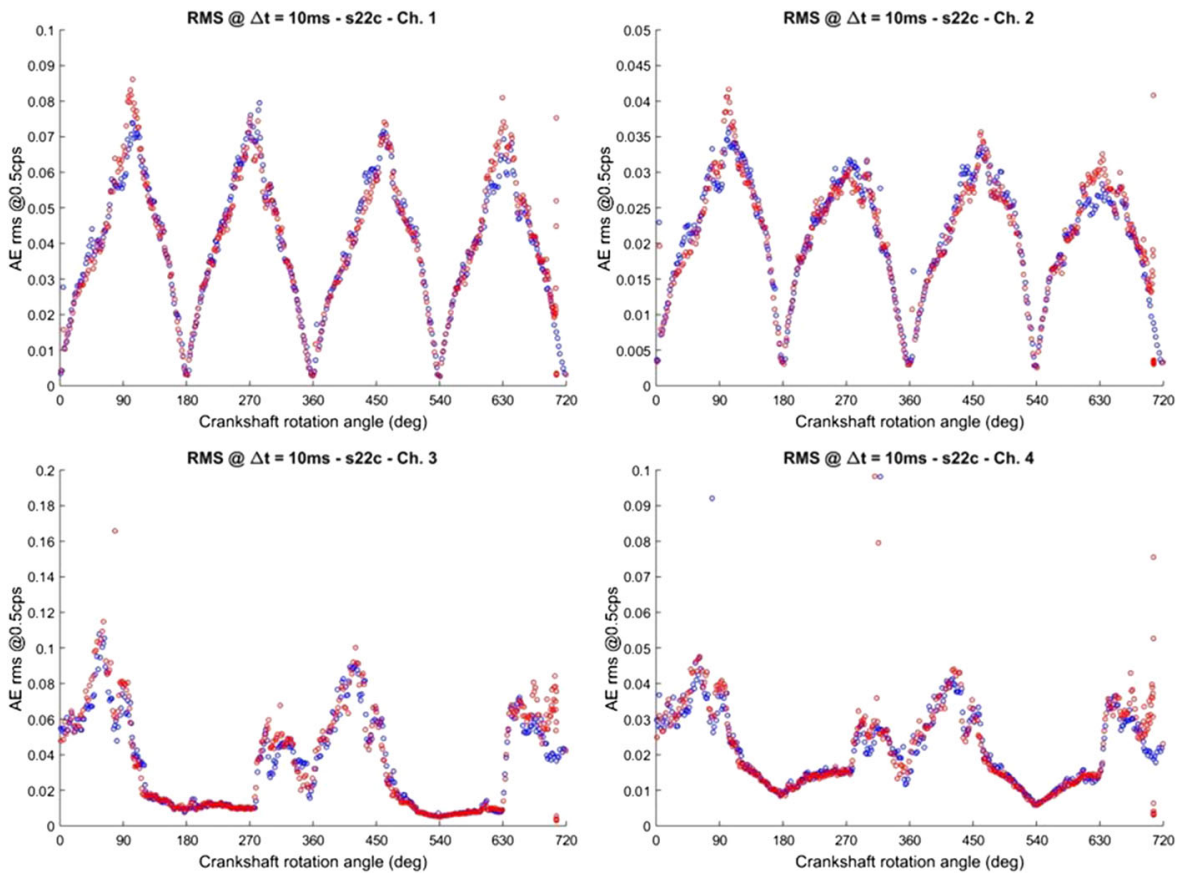

Fig. 7 Reference signals of the bench engine without spark plugs mounted

the sake of helping the reader to better understand the different steps of the time sequences related to the strokes of the engine presented in all the figures of AE signals, Table 1 and its accompanying figure lists all the respective positions of the pistons and of the valves during the engine cycles. 

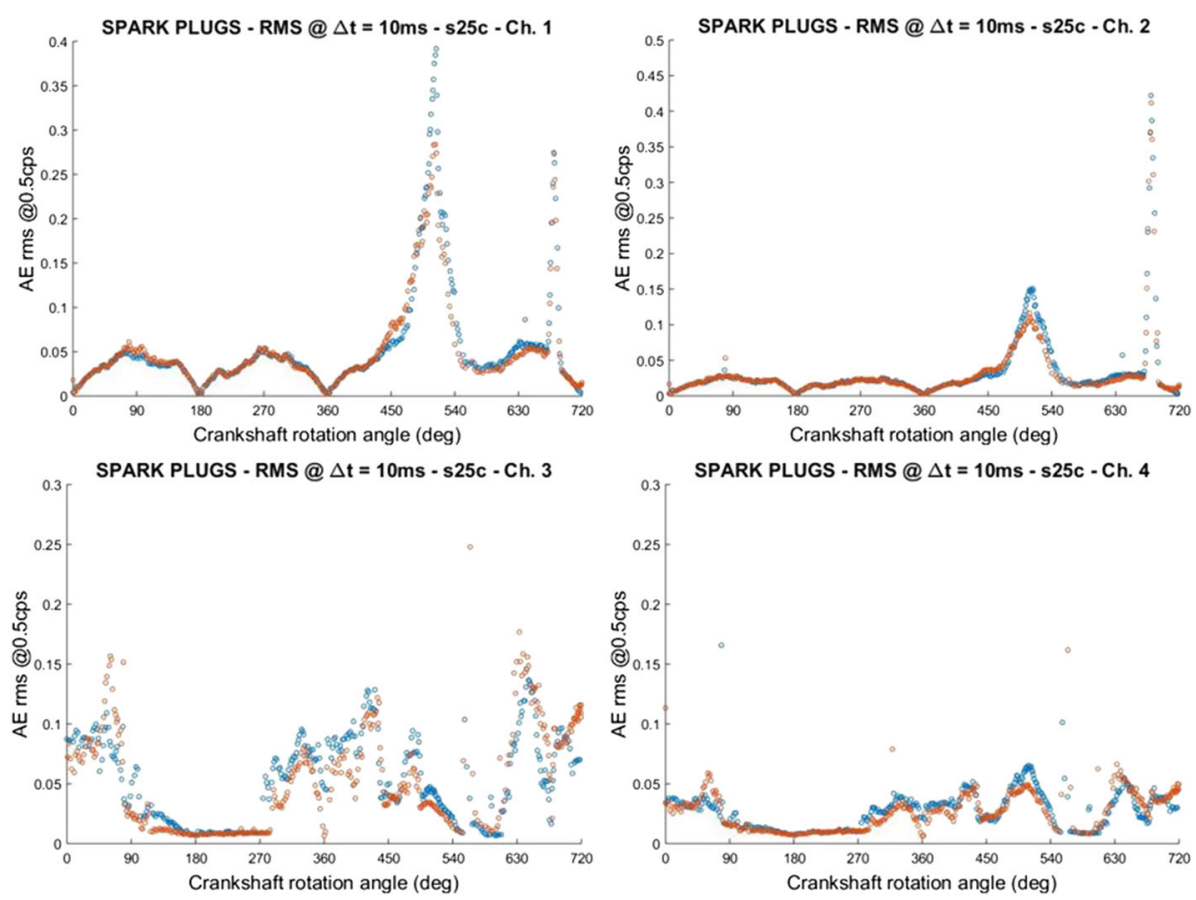

Fig. 8 Reference signals of the bench engine with the spark plugs mounted
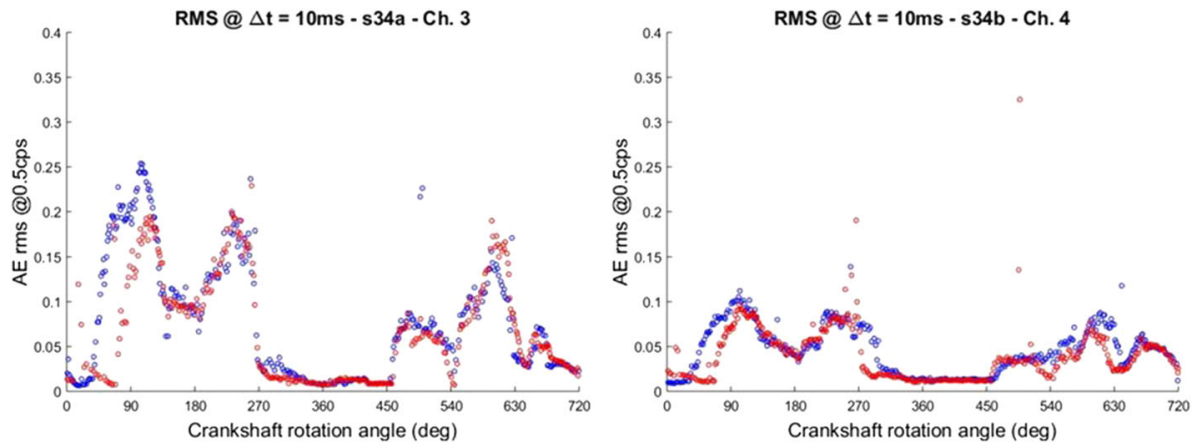

Fig. 9 Sensors signals showing the evidence of the clearance between the connecting rod and the crankshaft

\subsection{Clearance between the connecting rod and the crankshaft}

The signals recorded by sensors n. 3 and n.4 on the engine with a simulated clearance between the connecting rod and the crankshaft are reported in Fig. 9.

The signals measured during the simulation test related to the connecting rod failure are presented in Fig. 9 for sensors n.3 and n.4, in the context when the spark plugs are assembled. One may notice that the intensities of the signals are approximately doubled compared to the reference test (Fig. 8) for all the phases of the rotation of the crankshaft. This increase in intensity of the signals is attributed to the fact that the connecting rod is no longer correctly adjusted to the crankshaft, leading to a loose mechanical connection, 

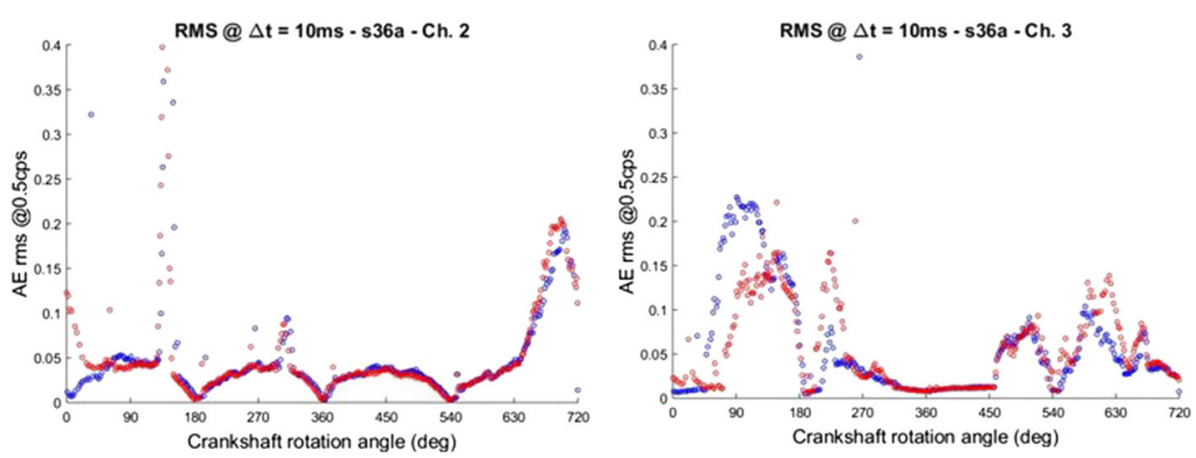

Fig. 10 Signals from sensors n.2 and n.3 where the clearance between piston pin $n .1$ and the connecting rod is visible
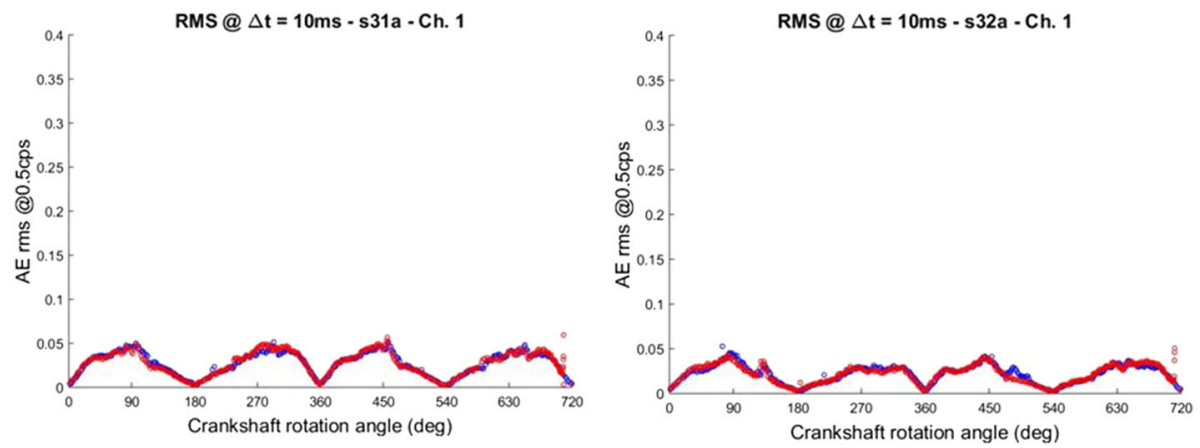

Fig. 11 a Cylinder n. 1 without rings, test without spark plug; b cylinder n.1 without rings, test with spark plug

allowing the rod to move inappropriately which creates shocks on the crankshaft itself that are recorded in particular by sensors n. 3 and n.4. Interestingly, the authors expected an even higher intensity in the positions where the pistons change direction, i.e. at top dead center (TDC) and bottom dead center (BDC), as reported in Table 1, nevertheless, the measurements did not reveal such a phenomenon. It is presumed that the additional signals due to the anomalous simulated movement may be masked by the other signals, or that they are attenuated while they propagate through the various parts of the engine, such as connecting rod, piston pin, piston, rings and finally the engine's block.

\subsection{Clearance between the piston pin and the connecting rod}

For the present failure simulation, the signals recorded by sensors $n .2$ and $n .3$ on the engine with additional clearance between the piston pin and the connecting rod are reported in Fig. 10.

The signal of sensor n.2 exhibited a strong intensity roughly doubled compared to the reference signals when compressing the cylinder $n .1$ before $720^{\circ}$ (Fig. 10). One assumption to explain this phenomenon is that the clearance between the piston pin and the connecting rod generates shocks during this phase of the engine cycle. Sensor $n .3$ also recorded stronger overall intensities compared to the reference signals. One may notice that, as in the case of the previous simulated failure, the enhanced peaks at TDC and BDC, that could be expected, are absent. 

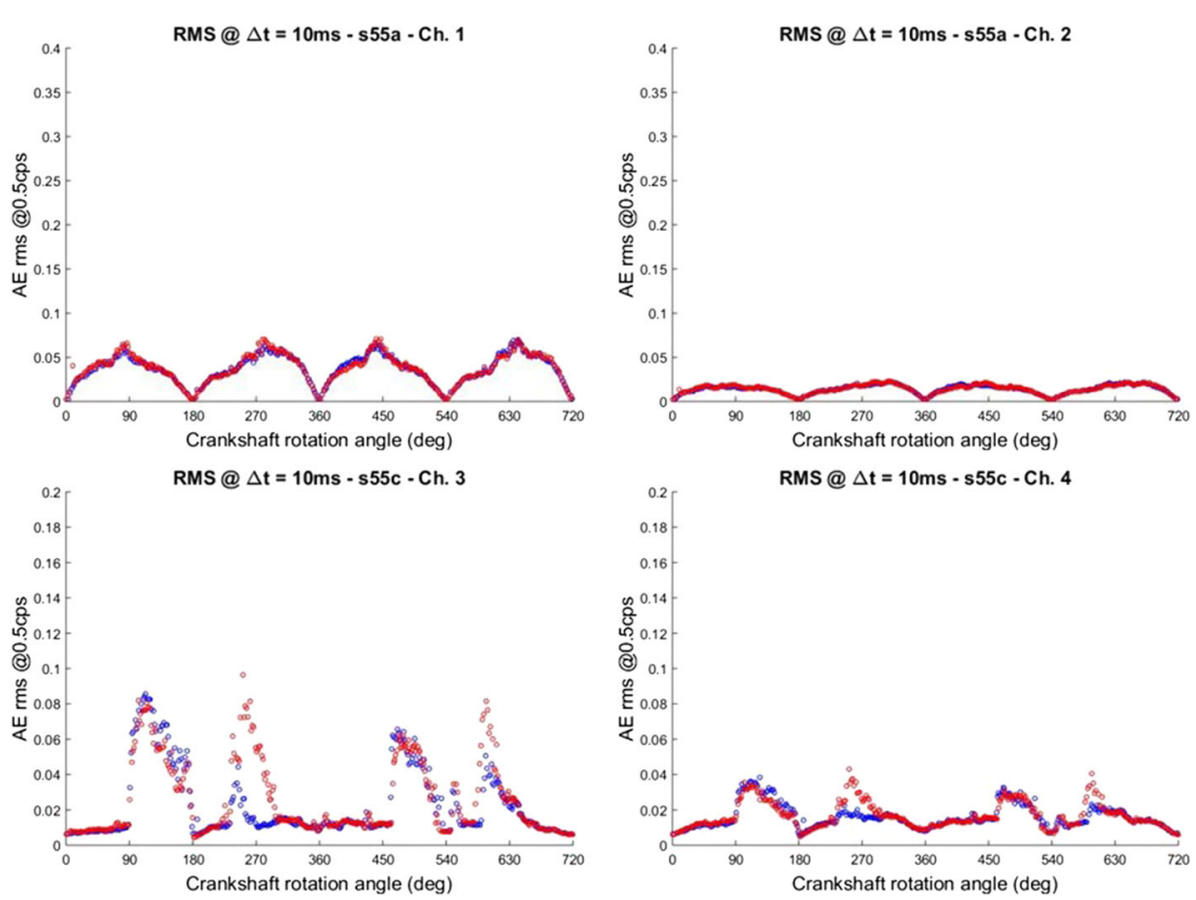

Fig. 12 Signals of the bench engine with the circuits filled and without spark plugs mounted

\subsection{Wear of the piston rings}

The signals recorded using the sensor $n .1$ on the engine during simulated wear of the piston rings are reported in Fig. 11.

When the rings are removed from the cylinder n.1, it can be noticed that the peak at $700^{\circ}$ that is visible in Fig. 10, channel 1, is absent in the present test ( spark plug mounted). This peak was attributed to the presence of a leak in cylinder $n .1$ that generates a characteristic acoustic signal when the compression in cylinder $n .1$ is highest (see cycles in Table $1,630^{\circ}$ to $720^{\circ}$ ). The signals with or without spark plugs are also identical (Fig. 11). Those two phenomena are related to the fact that without the rings, there is no longer any seal between the piston and the cylinder, and therefore no more compression. The intensity of the signals is also generally lower: 0.05 instead of 0.09 of the reference signal for this engine (Fig. 7) whether with or without spark plugs. As the rings no longer rub against the wall of the cylinder and therefore do not generate acoustic emission signals, the level of the signals related to the friction of the rings on the cylinders is attenuated.

\subsection{Test with filled circuits}

Once performed all the tests with simulated failures, the engine was reassembled to its original state. The cooling and lubrication circuits of the engine were filled in order to assess the influence of the presence of the fluids on the acoustic emission signals (Figs. 12, 13).

On the one hand, the signals recorded by sensors $n .1$ and n.2 have the same shapes as in the tests with empty circuits, nevertheless with lower intensities. It may be deduced that the presence of liquid causes a decrease in the amplitude as well as reduces the number 

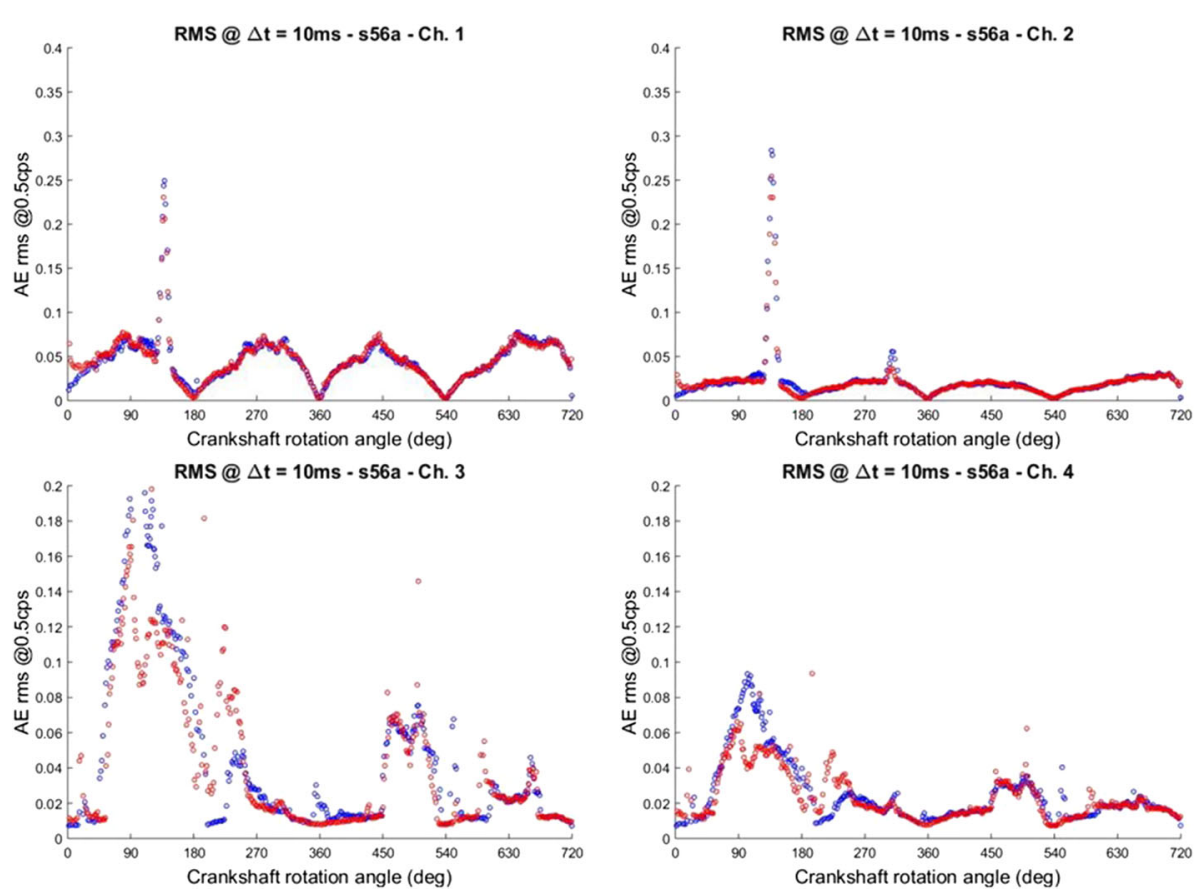

Fig. 13 Signals of the bench engine with the circuits filled and with spark plugs mounted

of characteristic acoustic emission signals. This is related to the fact that the water in the cooling circuit is now part of the wave propagation medium, thus causing the dissipation of the associated energy.

On the other hand, one may notice that the intensities of the signals measured by the sensors n. 3 and n.4 are higher than without fluid. These sensors record signals from the valvetrain, camshaft and crankshaft, which have been lubricated by filling the circuit with dedicated oil. It was expected that this operation would have, instead, reduced friction and therefore attenuated the signals emitted, as it was previously noticed during the tests for recording the reference signals [19]. An additional inspection of the engine allowed to discover, when the valvetrain case was opened to remove the crank drive system that a mechanical part was unexpectedly rubbing on the crankcase, which could explain the anomalously loud signals recorded.

\section{Conclusions}

The signals measured on an engine on which some commonly known malfunctions were simulated (controlled alteration) resulted to be significantly different from reference signals obtained on the same engine. The influence of a worn piston ring, a cast connecting rod failure or a clearance between a piston pin and the connecting rod are clearly retrievable from the specific obtained acoustic emission signals. The authors are of the opinion that acoustic emission has proven, therefore, its potential as a valuable tool for the detection of simulated failures in an historical vehicle's engine. One may expect that non-simulated failures (occurring outside the controlled context) could be identified as well. Nevertheless, 
Table 1 angular positions of pistons and valves during the engine cycles

\begin{tabular}{|l|l|}
\hline $\begin{array}{c}\text { Crankshaft } \\
\text { Angle } \mathbf{~}^{\circ} \text { ) }\end{array}$ & \multicolumn{1}{c|}{$\begin{array}{c}\text { Positions of the pistons and of the admission } \\
\text { valves }\end{array}$} \\
\hline 0 & $\begin{array}{l}\text { Top Dead Center (TDC)1 - explosion - } \\
\text { Bottom Dead Center (BDC) } 2\end{array}$ \\
\hline 16 & Admission 2 closed \\
\hline 90 & $\begin{array}{l}\text { Piston n.1 and n.2 at half stroke } \\
\text { The piston n.1 goes down and the n.2 goes up }\end{array}$ \\
\hline 180 & $\begin{array}{l}\text { TDC2 }- \text { explosion }- \\
\text { BDC1 }\end{array}$ \\
\hline 270 & $\begin{array}{l}\text { Piston n.1 and n.2 at half stroke } \\
\text { The piston n.2 goes down and the n.1 goes up }\end{array}$ \\
\hline 360 & $\begin{array}{l}\text { TDC1 } \\
\text { BDC2 }\end{array}$ \\
\hline 450 & $\begin{array}{l}\text { Piston n.1 and n.2 at half stroke. The piston n.1 goes } \\
\text { down and the n.2 goes up }\end{array}$ \\
\hline 540 & $\begin{array}{l}\text { TDC2 } \\
\text { BDC1 }\end{array}$ \\
\hline 630 & $\begin{array}{l}\text { Piston n.1 and n.2 at half stroke } \\
\text { The piston n.2 goes down and the n.1 goes up }\end{array}$ \\
\hline 720 & Rdmission 1 closed \\
\hline
\end{tabular}

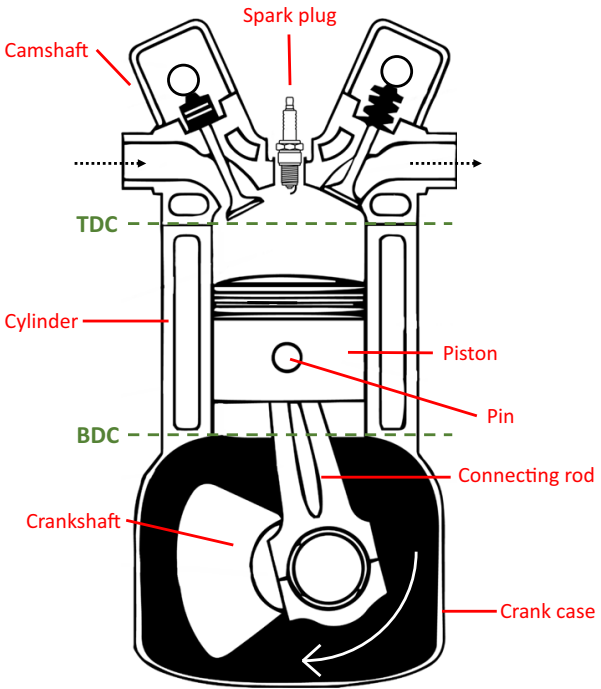

further experiment should be performed to assess whether these faults can also be identified on other engines of the same type or on historical engines in general.

Acknowledgements The authors would like to thank the HES-SO RCDAV for granting the ACUME_HV project, the MNAM for making the vehicles available for the measurements and $\mathrm{CD}$ for the manuscript proofreading.

Funding Open Access funding provided by Haute Ecole Specialisée de Suisse occidentale (HES-SO).

Open Access This article is licensed under a Creative Commons Attribution 4.0 International License, which permits use, sharing, adaptation, distribution and reproduction in any medium or format, as long as you give appropriate credit to the original author(s) and the source, provide a link to the Creative Commons licence, and indicate if changes were made. The images or other third party material in this article are included in the article's Creative Commons licence, unless indicated otherwise in a credit line to the material. If material is not included in the article's Creative Commons licence and your intended use is not permitted by statutory regulation or exceeds the permitted use, you will need to obtain permission directly from the copyright holder. To view a copy of this licence, visit http://creativecommons.org/licenses/by/4.0/.

\section{References}

1. C.B. Scruby, An introduction to acoustic emission. J. Phys. E Sci. Instrum. 20, 946-953 (1987)

2. S. Delvecchio, P. Bonfiglio, F. Pompoli, Vibro-acoustic condi-tion monitoring of internal combustion engines: a critical review of existing techniques. Mech. Syst. Signal Process. 99, 661-683 (2018). https:// doi.org/10.1016/j.ymssp.2017.06.033

3. B.C. Kaul, B. Lawler, A. Zahdeh, Engine diagnostics using acoustic emissions sensors. SAE Int. J. Engines (2016). https://doi.org/10.4271/2016-01-0639

4. P. Nivesrangsan, J.A. Steel, R.L. Reuben, Source location of acoustic emission in diesel engines. Mech. Syst. Signal Process. 21, 1103-1114 (2007)

5. N. Wei, J.X. Gu, F. Gu, Z. Chen, G. Li, T. Wang, A.D. Ball, An Investigation into the acoustic emissions of internal combustion engines with modelling and wavelet package analysis for monitoring lubrication conditions. Energies 12, 640-659 (2019). https://doi.org/10.3390/en12040640 
6. J.-D. Wu, C.-H. Liu, An expert system for fault diagnosis in internal combustion engines using wavelet packet transform and neural network. Expert Syst. Appl. 36, 4278-4286 (2009)

7. S. Johansson, P.H. Nilsson, R. Ohlsson, B.-G. Rosén, Experimental friction evaluation of cylinder liner/piston ring contact. Wear 271, 625-633 (2011)

8. R.M. Douglas, J.A. Steel, R.L. Reuben, A study of the tribological behaviour of piston ring/cylinder liner interaction in diesel engines using acoustic emission. Tribol. Int. 39, 1634-1642 (2006). https://doi.org/ 10.1016/j.triboint.2006.01.005

9. M.H. El-Ghambry, R.L. Reuben, J.A. Steel, The development of automated pattern recognition and statistical feature isolation techniques for the diagnosis of reciprocating machinery faults using acoustic emission. Mech. Syst. Signal Process. 17(4), 805-823 (2003). https://doi.org/10.1006/mssp.2002.1473

10. M. Shuster, D. Combs, K. Karrip, D. Burke, Piston Ring Cylinder Liner Scuffing Phenomenon Studies Using Acoustic Emission Technique (SAE International, Warrendale, 2000).

11. D.L. Carnì, C. Scuro, F. Lamonaca, R.S. Olivito, D. Grimaldi, Damage analysis of concrete structures by means of acoustic emissions technique. Compos. B Eng. 115, 79-86 (2017)

12. A. Carpinteri, G. Lacidogna, N. Pugno, Structural damage diagnosis and life-time assessment by acoustic emission monitoring. Eng. Fract. Mech. 74, 273-289 (2007)

13. A. Barontini, M.G. Masciotta, L.F. Ramos, P. Amado-Mendes, P.B. Lourenço, An overview on natureinspired optimization algorithms for structural health monitoring of historical buildings. Procedia Eng. 199, 3320-3325 (2017)

14. C. Scuro, P.F. Sciammarella, F. Lamonaca, R.S. Olivito, D.L. Carnì, IoT for structural health monitoring. IEEE Instrum. Meas. Mag. 21(6), 4-14 (2018)

15. A. Cariointeri, S. Invernizzi, G. Lacidogna, F. Accornero, Acoustic Emission monitoring of frescos degradation in a XVIIth Century chaper of the "Sacred Mountain of Varallo (Italy). Struct. Anal. Hist. Constr. 1-3, 2340-2348 (2012)

16. S. Le Conte, S. Vaiedelich, J.H. Thomas, V. Muliava, D. de Reyer, E. Maurin, Acoustic emission to detect xylophagous insects in wooden musical instrument. J. Cult. Herit. 16(3), 338-343 (2015)

17. D. Thickett, C.S. Cheung, H. Liang, J. Twydle, R.G. Maev, D. Gavrilov, Using non-invasive nondestructive techniques to monitor cultural heritage objects. Insight 59(5), 230-234 (2017)

18. A. Roda-Buch, E. Cornet, G. Rapp, B. Chalançon, S. Mischler, L. Brambilla, Development of a diagnostic tool based on acoustic emission techniques for historical vehicle's engines, in Proceedings of 31èmes JIFT, April 24-26, 2019, Tours, France (in press)

19. B. Chalançon, Les mesures d'émission acoustique appliquées aux moteurs d'automobiles de collection patrimoniale comme outil de diagnostic avant la remise en fonctionnement, MA Thesis HES-SO, Neuchâtel (2019)

20. L. Brambilla A. Roda-Buch, E. Cornet, G. Rapp, B. Chalançon, Diagnostics and Monitoring of Historical Vehicle Engines by Acoustic Emission Testing, in Proceedings of the 9th Interim Meeting of the ICOM-CC Metals Working Group, September 2-6, 2019, Neuchâtel (Switzerland)

21. A. Roda Buch, E. Cornet, G. Rapp, B. Chalançon, S. Mischler, L. Brambilla, Diagnostic of historical vehicle's engines by acoustic emission techniques, in Proceedings of the International Conference on Metrology for Archaeology and Cultural Heritage, December 4-6, 2019, Florence, Italy

22. A. Roda-Buch, E. Cornet, G. Rapp, B. Chalançon, S. Mischler, L. Brambilla, Fault detection and diagnosis of historical vehicle engines using acoustic emission techniques. Acta Imeko 10(1), 77-83 (2021)

23. R. Keller, P. Garnier, National Car Museum Schlumpf Collection Mulhouse France. Du Donon editor, Strasboug (France). ISBN 978-2914856744 (2014), p. 80 